\title{
Controlling groundwater pollution from petroleum products leaks
}

\author{
M. S. Al-Suwaiyan \\ Civil Engineering Department, \\ King Fahd University of Petroleum and Minerals, Saudi Arabia
}

\begin{abstract}
Groundwater is the main source of potable water in many communities. This source is susceptible to pollution by toxic organic compounds resulting from the accidental release of petroleum products. A petroleum product like gasoline is a mixture of many organic compounds that are toxic at different degrees to humans. These various compounds have different characteristics that influence the spread and distribution of plumes of the various dissolved toxins. A compositional model utilizing properties of organics and soil was developed and used to study the concentration of benzene, toluene and xylene (BTX) in leachate from a hypothetical site contaminated by BTX. Modeling indicated the high and variable concentration of contaminants in leachate and its action as a continuous source of groundwater pollution. In a recent study, the status of underground fuel storage tanks in eastern Saudi Arabia and the potential for petroleum leaks was evaluated indicating the high potential for aquifer pollution. As a result of such discussion, it is concluded that more effort should be directed to promote leak prevention through developing proper design regulations and installation guidelines for new and existing service stations.
\end{abstract}

Keywords: groundwater pollution, petroleum products, dissolved contaminants, modelling contaminant transport.

\section{Introduction}

Water covers about $73 \%$ of our planet with a huge volume of 1.4 billion cubic kilometers most of which is saline. According to the water encyclopedia [1], only about $3-4 \%$ of the total water is fresh. Most of the freshwater exist as ice in the polar region leaving about 9 million cubic kilometers of fresh water existing 
as groundwater and surface water. Looking at numbers one will realize that most fresh water on earth exists as groundwater making it arguably the most valuable resource on earth.

The value of this resource can be reduced drastically if its quality deteriorates. A common source for groundwater pollution is hydrocarbon leaks from underground storage tanks which happen due to improper design, human error, accidents, or simply due to the natural aging and deterioration of the tank itself or its associated piping and fittings.

An underground storage tank (UST) or its associated piping may leak, releasing a certain volume of hydrocarbon into the subsurface. Depending on the spill volume, type and subsurface properties, the hydrocarbon may be trapped in the unsaturated zone. For high spill volume, it will continue to migrate down reaching close to the water table. The mobile phase near the water table can migrate laterally in the same direction as groundwater. Part of the hydrocarbon will dissolve slowly in the groundwater providing a long term source of groundwater contamination by means of a contaminated plume that grows in size with time [2].

The major steps involved in dealing with spills and trying to restore the subsurface have to do, in the initial phase, with source control and development of thorough understanding of the subsurface conditions and the extent of contamination which should be followed by intensive use of modeling techniques in order to examine and select the most effective means of aquifer restoration and to examine the system behavior under various possible scenarios.

\section{Contamination assessment and monitoring}

Field investigation at this stage aims at assessing the extent of contamination and knowing the distribution of the released contaminants. It may involve sampling of aquifer material, construction of wells screened in hydrocarbon zone and wells screened below the water table, which can provide information such as thickness of hydrocarbon in wells, concentration of dissolved contaminants as well as approximate water table elevation. These are the primary data that must be used to evaluate nature and extent of groundwater pollution. Soil samples collected during the field investigation can be taken to the laboratory to get their grain size distribution which may be in turn used in models such as the one presented by Mishra et al. [3] to generate a first approximation for the hydraulic properties of the subsurface. A review for estimating spill volume is presented by Saleem et al. [4].

It is well established that monitoring wells are not reliable for spill detection and quantification since in many field cases, leaks are accidentally discovered by detecting free product in utility manholes not by finding free product monitoring wells.

\section{Distribution of contaminants}

Farr et al. [5] as well as Lenhard and Parker [6] showed that the vertical distribution of a hydrocarbon after a spill is expected to be influenced by the spill volume, soil properties like displacement head, distribution index and value of 
residual saturation. These properties reflect the grain-size distribution in the aquifer material which varies significantly from one location to another. Hydrocarbon properties also influence its distribution including density, surface tension, viscosity, solubility and volatility. In general a hydrocarbon can exist in either of four classes. It can be held by capillary and adsorptive forces in the unsaturated/saturated zone as residual or immobile phase which approximately remain in its place but slowly dissolving part of its mass with any water flow. It can also exist as a vapor phase in the unsaturated zone or as free phase near the water table and in monitoring wells. Finally it can exist as a dissolved phase in groundwater at relatively very low concentrations but note that most of these products are very harmful to humans even at trace levels.

\section{Subsurface near petroleum processing facilities}

The subsurface near petroleum processing facilities or aging service station most likely will contain many organic compounds originally existing in oil. Among these compounds are benzene, toluene and xylene (BTX). BTX are common organic pollutants associated with accidental leaks of common fuels. Their presence in the subsurface will result eventually in groundwater contamination which can create a hazard affecting human health. The health effects associated with long term expose to these products according to EPA [7] include chromosome aberrations, cancer, liver and kidney damage, damage to central nervous system, nervous disorders including spasms, tremors, impairment of speck, hearing, vision, memory, coordination. National Primary Drinking Water Regulations [7], give maximum contaminant levels (MCL) of $5 \mathrm{ppb}, 1 \mathrm{ppm}, 10 \mathrm{ppm}$, for benzene, toluene and xylene respectively. To assess the degree of possible groundwater pollution from an accidental spill, the characteristics of the leachate from the contaminated zone, mainly pollutant concentrations has to be studied which can be done by developing a compositional model.

\section{Modeling leachate characteristics}

Consider the hypothetical subsurface near a petroleum processing facility shown in fig. 1. The shaded area near ground surface represents an idealized zone polluted by residual amounts of BTX. As water infiltrates due to precipitation, irrigation or process activities, it will leach these contaminants slowly forming a continuous source of contamination into the underlying unconfined aquifer. In this section a model to study this process will be developed.

\subsection{Leaching model development}

After a hydrocarbon spill in the vadose zone its components will partition between four possible phases, namely water, air, soil and free hydrocarbon. For each component the concentration in water is related to the bulk concentration through [8]:

$$
m_{i}=B_{w_{i}} C_{w_{i}}
$$




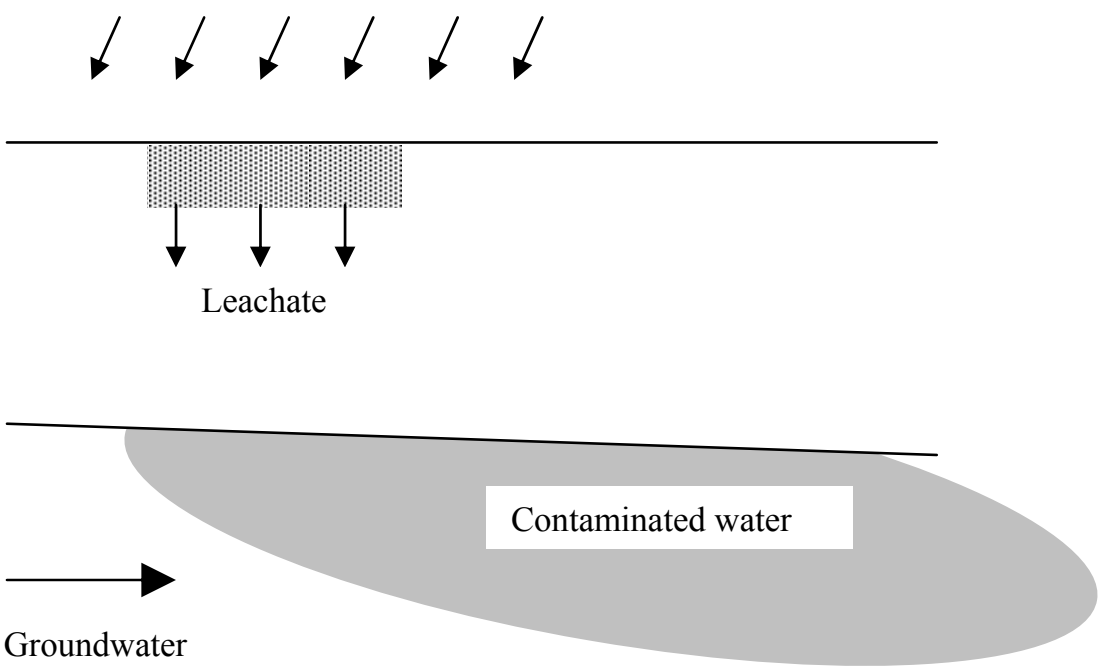

Groundwater

Figure 1: $\quad$ Schematic view for contaminated soil and groundwater aquifer.

where:

$\mathrm{m}_{\mathrm{i}}=$ bulk concentration of compound $\mathrm{i}$

$\mathrm{B}_{\mathrm{w}_{\mathrm{i}}}=$ bulk water partitioning coefficient for compound $\mathrm{i}$

$\mathrm{C}_{\mathrm{w}_{\mathrm{i}}}=$ concentration of compound $\mathrm{i}$ in water

The bulk water partitioning coefficient will be influenced by component volatility, adsorption properties as well as the distribution of compound in the free hydrocarbon.

Applying principle of mass balance will allow us to develop the concentration of pollutants in leachate as a function of time as outlined by Charbenuea [8].

Referring to fig. 1 , the total mass present for compound $i$ is given by:

$$
M_{i}=A L_{o} B_{w_{i}} C_{w_{i}}
$$

where:

$\mathrm{M}_{\mathrm{i}}=$ total mass of compound $\mathrm{i}$

$\mathrm{A}=$ area of contaminated zone

$\mathrm{L}_{0}=$ depth of contaminated zone

Neglecting volatility and degradation and assuming mass is lost only with leaching water, the mass balance equation becomes:

$$
\frac{\mathrm{d} \mathrm{M}_{\mathrm{i}}}{\mathrm{dt}}=\frac{\mathrm{d}}{\mathrm{dt}}\left[\mathrm{A} \mathrm{L}_{\mathrm{o}} \mathrm{B}_{\mathrm{w}_{\mathrm{i}}} \mathrm{C}_{\mathrm{w}_{\mathrm{i}}}\right]=-\mathrm{qA} \mathrm{C}_{\mathrm{w}_{\mathrm{i}}}
$$


The above equations can be solved numerically to come up with the BTX concentrations at various times.

\subsection{Modeling results and discussion}

The above model was applied to the hypothetical case shown in fig. 1, using typical values for the parameters involved. These values include a porosity of 0.45 , a water flow rate of $1 \mathrm{~cm} /$ day, and an average moisture content of 0.225 , and a residual hydrocarbon content of 0.0675 . A contaminated depth of $10 \mathrm{~cm}$ was selected and the contaminating mixture consisted of equal volumes of BTX. The model was run to generate the concentration of the three organic compounds in the leachate and their temporal variation.

The characteristics of the leachate can be examined through fig. 2, which indicates that at early times, benzene acts as the dominant pollutant affecting groundwater. Benzene concentration decreases at a relatively sharp rate. After about seven months, toluene takes over as the main pollutant and assumes that

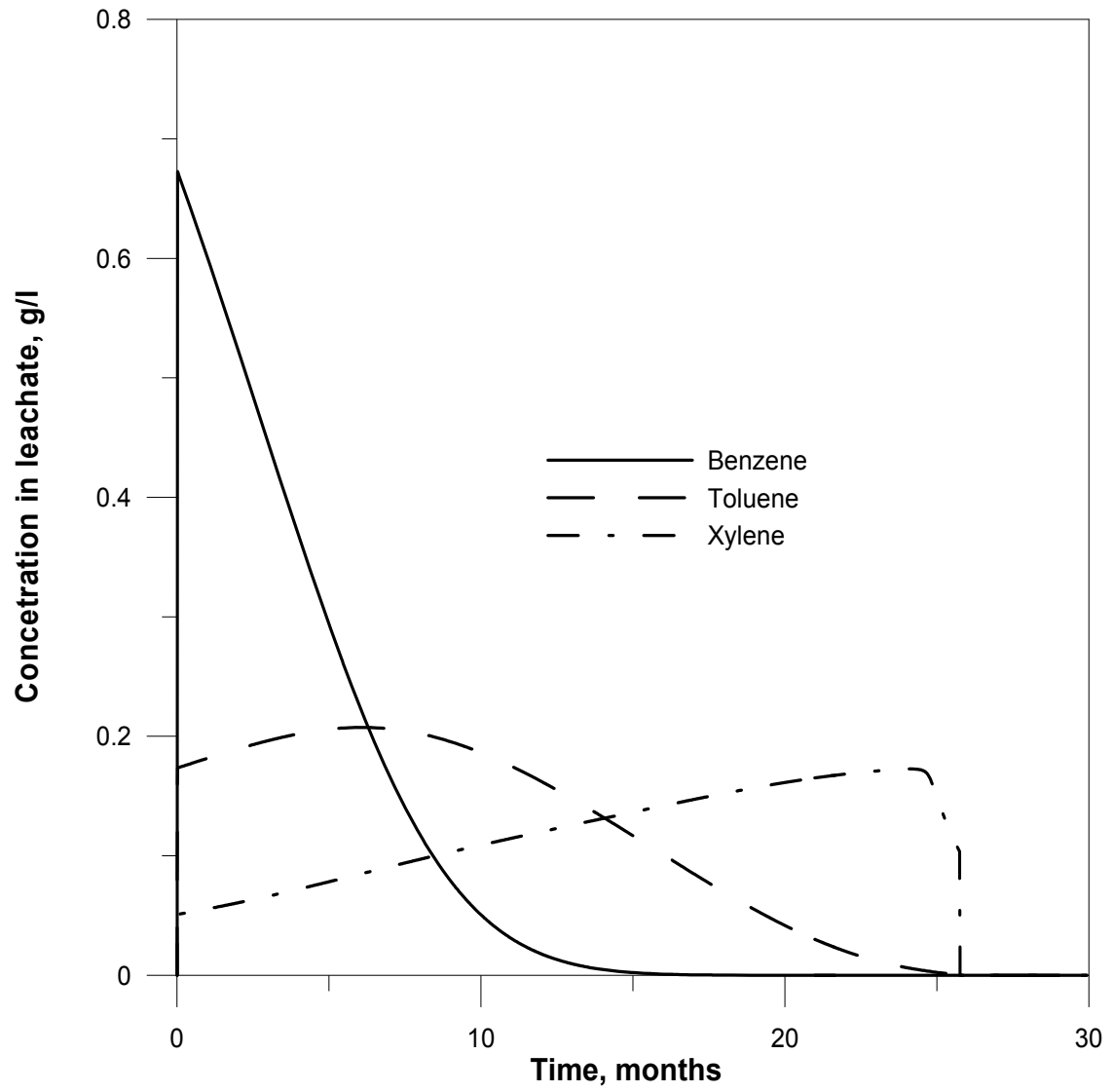

Figure 2: Aqueous concentration for different compounds in leachate. 
role for eight months before xylene catches up and becomes the more significant pollutant. Since the three compounds have close affinity to the soil matrix, the variation in the compound concentration in the leachate could be explained by realizing that benzene has a solubility in water that is about three times as much as toluene and ten times compared to xylene. Examining the values from fig. 2, it is clear that the concentration levels are much higher than the MCLs and that as one concentration decreases the others take over which is expected to have a drastic effect on the underlying aquifer. The mass per unit area of the zone of contamination that eventually will reach the water table for the three compounds is shown in fig. 3. Notice that initially benzene is the main pollutant leveling in ten months. The contaminants concentration in groundwater will be obviously affected by this variable source by resulting in a pollution plume with variable characteristics making the remediation process more difficult. The leaching process will result in reducing the hydrocarbon in the vadose zone initially at a higher rate. However as the process continues the rate becomes much smaller

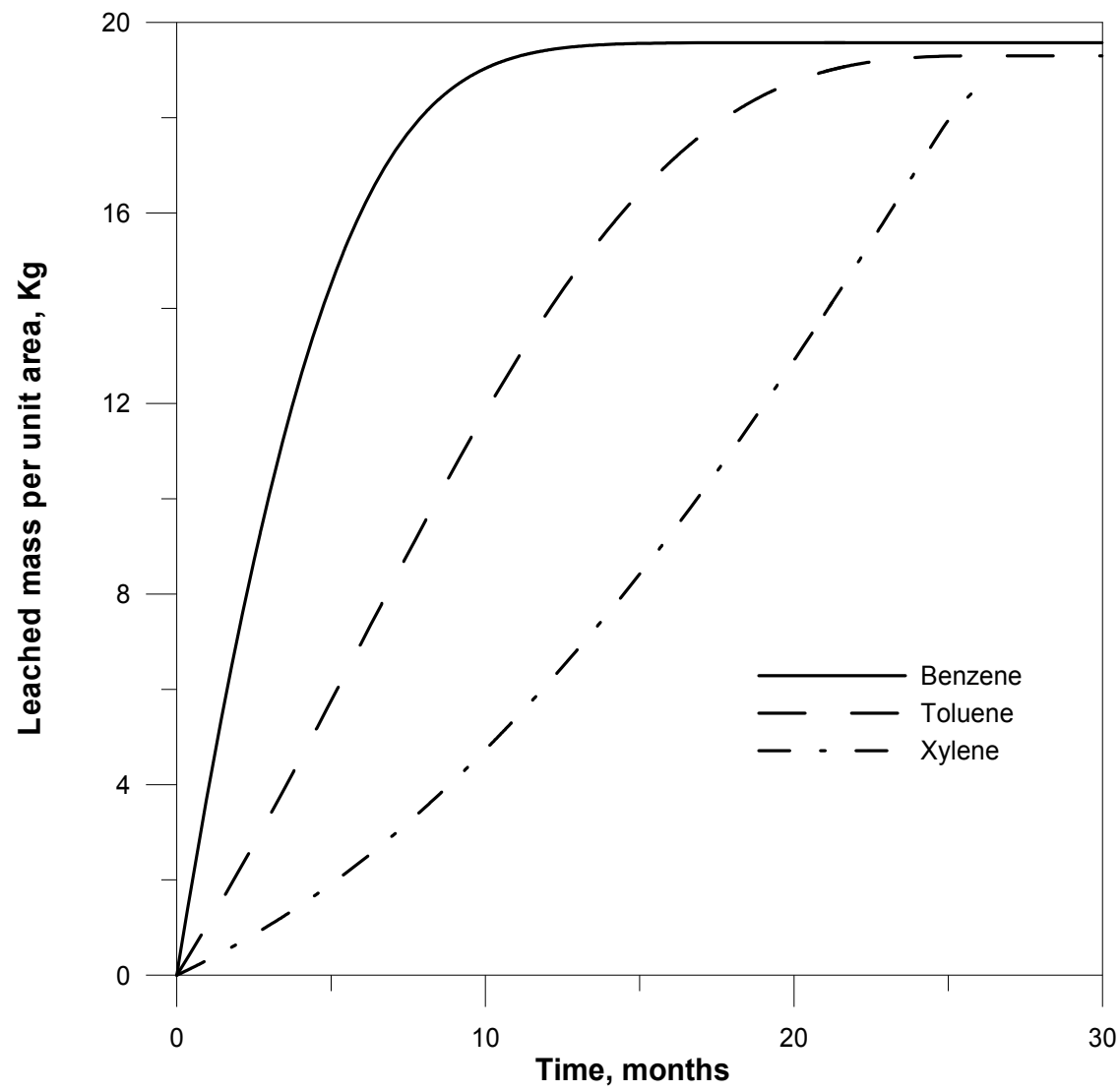

Figure 3: Total mass (pollution source) entering groundwater with the leachate. 
(see fig. 4). The influence of the water flow rate is examined by plotting the residual hydrocarbon content for different rates as shown in fig. 4. Careful examination of the figure reveals that although higher water flow rate results in quicker removal of contaminants from the soil matrix, it takes it also transport the pollutants to groundwater faster. On the other hand lower water rate leads to slow but long acting pollution source.

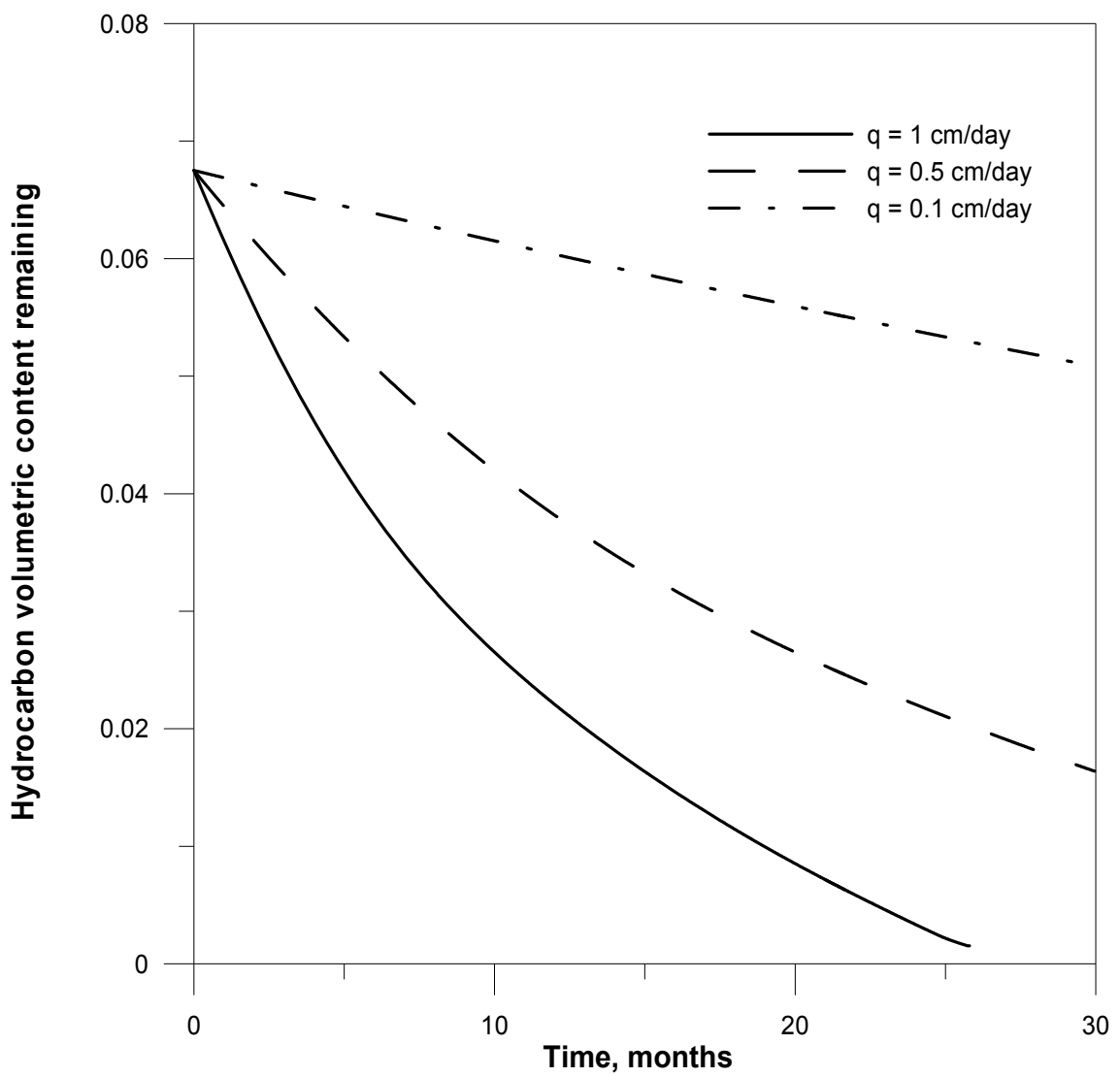

Figure 4: Hydrocarbon volumetric content remaining in vadose zone for different water flow rates.

The values used for this modeling study, in particular the water flow rate, might be very high, however it was selected in order to make assumptions like negligible contaminant degradation acceptable.

\section{Status of fuel storage tanks in Saudi Arabia}

In a recent study (Al-Suwaiyan et al. $[9,10])$ a survey and site visits were conducted in order to evaluate the potential risk of groundwater pollution due to underground fuel storage tanks. Important information related the storage tanks, 
routine monitoring, maintenance, preventive maintenance as well as laws and regulation existence as well as enforcement were collected and reviewed. The results revealed that a significant number of service stations had old tanks made using reinforce concrete and that they never received maintenance which is a must given the aggressive subsurface environment. The study also showed the lack of protection from corrosion and only about $20 \%$ had cathodic protection. Any monitoring was absent in close to $60 \%$ of the service stations surveyed. Similarly, emergency response practices were lacking. Given the limited geographical area for this study, it still can be expected to roughly represent the actual conditions in many developing countries. This lack in all aspects, leads one to conclude that the risk for contaminating the underlying aquifers is high.

\section{Summary and Conclusion}

A compositional model was developed in order to simulate BTX concentrations in leachate from a subsurface contaminated by residual hydrocarbon. The model was also used to estimate the mass of contaminants that reach an underlying water table as well as quantifying the amounts remaining in the contaminated zone. The modeling results indicated the existence of very high concentrations of BTX in the leachate and it also revealed the long time effect of such pollution. The effect of the percolation rate was also studied to conclude that high flow rate will case quicker cleanup but higher concentration in groundwater and vice versa. Modeling is an essential part of remediation projects and any design or selection of operating condition and in turn the overall performance will be influenced by how accurately real conditions were presented in the model. This accounts for the fact that remediation of contaminated aquifers is rarely successful. Review of the status of underground fuel storage tanks at service stations in eastern Saudi Arabia could be extrapolated to some developing countries suggesting good potential for soil and groundwater pollution at many locations sooner or later. One way to avoid such problem could be through reducing or preventing, if possible, groundwater contamination in the first place by regulating underground fuel storage tanks and requiring continuous maintenance and monitoring.

\section{Acknowledgement}

The support provided by the Civil Engineering Department at King Fahd University of Petroleum and Minerals is highly appreciated.

\section{References}

[1] Van der Leeden, F., Troise, F.L. and D.K. Todd, (eds.). The Water Encyclopedia, $2^{\text {nd }}$ ed., Lewis Publishers, Chelsea, MI, 1990. 
[2] Al-Suwaiyan, M.S., Bashir, K., Aiban, S.A. and Ishaq, A.M., Analytical model to quantify crude oil spills in sandy layered aquifers. Journal of Environmental Engineering, ASCE, 128(4), pp. 320-326, 2002.

[3] Mishra, S., J. C. Parker, and N. Singhal, Estimation of soil hydraulic properties and their uncertainty from particle size distribution data. Journal of Hydrology 108, pp. 1-18, 1989.

[4] Saleem, M. Al-Suwaiyan, M., Aiban, S., Ishaq, A.M., Al-Malack, M. and M. Hussain. Estimation of spilled hydrocarbon volume-the state-of-the-art, Environmental Technology, 25(9), pp 1077-1090,2004.

[5] Farr, A.M., R.J. Houghtalen, and D.B. McWhorter, Volume estimation of light nonaqueous phase liquids in porous media, Ground Water 28(1), pp. 48-56,1990.

[6] Lenhard, R.J., and J.C. Parker, estimation of free hydrocarbon volume from fluid levels in monitoring wells, Ground Water 28(1), pp. 57-67, 1990.

[7] United States Environmental Protection Agency (USEPA). The Office of Ground Water \& Drinking Water Web Site, Washington DC, http://www.epa.gov/OGWDW

[8] Charbeneau, R.J., Groundwater Hydraulics and Pollutant Transport, Upper Saddle River, New Jersey: Prentice -Hall, 2000.

[9] Al-Suwaiyan, M.S., A.M. Ishaq, M.H. Essa and M. Saleem, Assessment of the status of USTs at service stations in eastern Saudi Arabia. Proc. of the Fourth Saudi Technical Conference, Riyadh, pp. 286-293, 2006.

[10] Al-Suwaiyan M.S., A.M. Ishaq, M.H. Essa and M. Saleem, Environmental Pollution Due to Underground Fuel Storage Tanks: a)assessment; b) guidelines for prevention, KACST, Riyadh, 2008. 